Article

\title{
Designing for Inclusivity: Platforms of Protest and Participation
}

\author{
Michael Leyshon * and Matthew Rogers \\ Centre for Geography and Environmental Science, University of Exeter, Penryn, TR10 9FE, UK; \\ E-Mails: m.leyshon@exeter.ac.uk (M.L.), m.j.rogers@exeter.ac.uk (M.R.) \\ * Corresponding author
}

Submitted: 15 May 2020 | Accepted: 3 August 2020 | Published: 14 October 2020

\begin{abstract}
This article offers critical insights into new digital forms of citizen-led journalism. Many communities across western society are frequently excluded from participating in newsgathering and information dissemination that is directly relevant to them due to financial, educational and geographic constraints. News production is a risky business that requires professional levels of skill and considerable finances to sustain. Hence, 'hyper-localised news' are often absent from local and national debates. Local news reportage is habitually relegated to social media, which represents a privileged space where the diffusion of disinformation presents a threat to democratic processes. Deploying a place-based, person-centred approach towards investigating news production within communities in Cornwall, UK, this article reflects on a participatory action research project called the Citizen Journalism News Network (CJNN). The CJNN is an overt attempt to design disruptive systems for agenda setting through mass participation and engagement with social issues. The project was delivered within four communities via a twelve-week-long journalism course, and a bespoke online app. CJNN is a platform for citizen journalists to work collaboratively on investigating stories and raising awareness of social issues that directly affect the communities reporting on them.
\end{abstract}

\section{Keywords}

citizen journalism; digital innovation; disruptive networks; online platforms

\section{Issue}

This article is part of the issue "The City of Digital Social Innovators" edited by Chiara Certomà (Ghent University, Belgium), Antonella Passani (T6-Ecosystems, Italy) and Mark Dyer (University of Waikato, New Zealand).

(C) 2020 by the authors; licensee Cogitatio (Lisbon, Portugal). This article is licensed under a Creative Commons Attribution 4.0 International License (CC BY).

\section{Introduction}

The long hailed digital dawn of the Internet where all voices are equally well-received within an egalitarian framework, and all available channels of representation for participation are clearly signposted, appears to have been delayed and overshadowed by the desire to secure profits through proprietorial systems that enforce subscription models of access. The tools are available within Europe and beyond to enable an effective and proportional representation of the population via Internet connectivity, however, incentives for individuals to participate in public debate are few in a habitus conditioned by a paradigm of exclusionary cultural communicative traditions and the rip-tides of popular public opinion and pro- priety that surround, depend upon and rigorously defend the status quo. Innovative and socially disruptive systems that emerge are (more often than not) both facilitated by and in response to specific sets of economic and cultural frameworks.

The global financial crisis of $2008 / 9$ precipitated in many western economies the introduction of austerity measures across public social programmes. Governments attempting to address the effects of financial precarity and meet the growing demands of diverse societies have encouraged organisations and agencies to develop and deliver digital social innovations to ameliorate a range of social issues. Although there is considerable debate about the meaning and use of the term social innovation (and overlaps with other activi- 
ties such as social enterprise and the social economy), it broadly refers to the ways in which human societies adapt to meet new challenges. Contemporary debates about collective responses to a range of social issues reflect the ways in which human societies both create and adapt to new challenges, experimenting with policy and practical innovations in order to solve collective concerns (Moulaert, Mehmood, MacCallum, \& Leubolt, 2017). Hyperlocal-news reporting is one such innovation. In this article we respond to Hess and Waller's (2016) appeal to resituate research on hyperlocal-news reportage within alternative frameworks. We argue that citizen journalism provides an opportunity for publics to engage with local democracy and the politics of the public sphere (Harte, Williams, \& Turner, 2017). This is achieved through the deployment of a co-designed digital social innovation (DSI) platform: Citizen Journalism Network (CJN). In the following section we discuss how DSIs can contribute to social change before going on to explore their role in citizen journalism.

\section{Digital Social Innovations}

DSIs are presented as a way of harnessing the operative possibilities of the Internet to: (1) encourage dynamic social relationships between previously separate individuals and groups; (2) meet pressing unmet social needs and improving the lives of people by drawing publics into the problem-solving process (Edwards-Schachter \& Wallace, 2017; Mulgan, 2006); and (3) help organisations to adapt processes or respond to new issues in a flexible and pragmatic way.

The range of DSIs is astonishing, from collectivising people who have similar issues from health, economic and social concerns (Evans \& Gawer, 2016; Mason, Barraket, Friel, O'Rouke, \& Stenta, 2015; Moulaert et al., 2017) via social networks (Muller \& Peres, 2019), to online platforms for citizen participation in policymaking (Angelidou \& Psaltoglou, 2017), to using 'big data' or open data sources to produce more transparency around public spending to participatory budgeting (Bria, 2015). This growing interest in DSIs is generally associated with the potential power of civil society and community-led action to develop responses to urban social concerns (Moulaert, Swyngedouw, Martinelli, \& Gonzalez, 2010). Rather than calling on government to act for people, as was common during the social democratic experiments of the twentieth century, particularly in Western Europe, the emphasis now is on public engagement through codesign. DSIs are essentially "a type of collaborative innovation in which innovators, users and communities cocreate knowledge and solutions for a wide range of social needs exploiting the network effect of the Internet" (Schon, Ebner, \& Hornung-Prahauser, 2017, p. 1).

DSI is often cited as a fast fix or panacea for the challenges facing societies, through delivering improved quality of service and operational and cost-saving efficiencies (Dodd, 2015; Lloyd, Jochum, \& Hornung, 2017).
They are also often predicated on the production of platforms through which organisations, agencies and individuals can connect to each other. To date, platforms have mainly been approached as a phenomenon, rather than as a metaphor or an analytic for social form. Formally, platforms build upon but are-in important ways-distinct from networks, most notably through their 'programmable space' that can be made to perform differently according to how external networks engage. Just as networks indicate the importance of form for understanding the socio technical, DSI platforms must also be approached as a heuristic for understanding the form of social relations.

Regarding urban digital futures, DSIs have the capacity to produce and augment new material and social organisational arrangements. This approach requires the co-design of DSI platforms, but also includes broader materialisations of the social forms of platforms. Across Europe there have been a range of DSI projects aimed at encouraging cities to work together through a network of knowledge exchange and digital practices, such as the CAPS (Collective Awareness Platforms for Sustainability and Social Innovation) programme (for a detailed review of these projects see Bria, 2015; Cangiano, Romano, \& Loglio, 2017). The case study of this article, Cornwall, is part of the UK Digital Strategy (Department of Culture, Media and Sport, 2017) and the UK's Civil Society Strategy (Cabinet Office, 2018), which promotes digital technologies to address social challenges. The UK government is "committed to bringing together digital and civil society" (Cabinet Office, 2018, p. 83) through the triple helix approach whereby the voluntary, private and public sectors work together to deliver DSI.

This article examines critically the role and function of DSIs within citizen led journalism. It is within the uncomfortable and challenging interface between individual actions and the collective responsibilities of societies at large that the citizen journalist identifies, observes and reports on their situation(s) of interest, often proactively both inhabiting and responding towards issues of personal interest and personal experience. There is also an active and ongoing dispute between the ethically liberated and financially unfettered actions of the citizen journalist and the industrially embedded and ethically rooted authorial attributes of the professional journalist (Forde, 2011; Williams, Harte, \& Turner, 2015). The direct first-hand experiences of the citizen journalist may ensure they are incapable or uninterested in adhering to the traditional journalistic behaviours that attempt to ensure impartial and unbiased reporting. The Citizen Journalism News Network (CJNN) project detailed in the next section applies Downing's (2001, p. 388) "hexagon of radical media" as a guiding framework to encourage the engagement of citizen journalists within the essentially polarised and unresolved spaces between the social and the individual or the personal and the public. 


\section{Digital Citizen Journalism as Place Making}

The advent of digitally networked systems for the creation and dissemination of news media have upended the traditional news practices of national and local professional news providers (Anderson, Bell, \& Shirky, 2012). Claire Enders' (2011) report to the Leveson Inquiry in 2011 found that revenues for local news provision have dropped from between $23-50 \%$. This has resulted in an increase in the provision of franchised news services and the subsequent reduction of local narratives and references to place within local news. As Williams et al. (2015) suggest, much of the output of UK hyperlocal news provides an opportunity for local citizens and community groups to contribute to the plurality of local media through reporting on cultural and civic life, local economies, as well as local politics.

Digital technologies have generated an exponential number of two-way access points for a news system that was previously considered to be a closed circuit. Globally networked social media platforms have shrewdly interpolated the opportunities that contemporary communication technologies present to their users whilst at the same time adroitly capitalising upon the demand for digitally mediated interpersonal communications and the new set of creative communication options (Papacharissi, 2014). "The rise of algorithms and platforms that enable individual users and services to take part in publishing news has changed gatekeeping selection processes and news flow patterns" (Wallace, 2018 , p. 275), placing a number of international technology companies in the position of being market leaders in global communications and bequeathing them the position of gatekeepers to global, national and local news markets that often treat borders as invisible, content as non-exclusive, news brands as interchangeable and traditional news organisation's business models as antiquated.

The up-shift from inert consumers of the news to active commentators, contributors, distributors and creators of the news has opened up manifold possibilities to study emerging behaviours, relationships and discourses (McCollough, Crowell, \& Napoli, 2017). The CJNN project applied iterative design methodologies to create a hyperlocal, networked, news gathering platform as a tool for listening to marginalised members of rural communities within Cornwall. The starting point was the desire to engender agency and personal representation within a series of identified hyper-local minority communities within Cornwall that have traditionally been excluded from or unable to take up such opportunities.

\section{Case Study Area: Cornwall, UK}

Cornwall is one of the poorest areas of the UK and has seventeen areas that are ranked amongst the most deprived 10\% in England (Cornwall Council, 2015). Since 2000 Cornwall has received $£ 350$ million in funding from the European Union via the Objective 1 programme to boost the economy and ameliorate the worst extremes of severe deprivation (Cataldo, 2016). Those who financially struggle in Cornwall face a range of types of exclusion, digital, financial, social and wellbeing, leaving vulnerable groups behind (Dwyer \& Wright, 2014; Turnbull, 2016). Digital exclusion is a social problem as much as a technological one, making it hard to access services online, including Universal Credit (Cornwall and Isles of Scilly Leadership Board, 2019). Financial exclusion follows from digital exclusion, as those most vulnerable are excluded from managing monies online (Travers-Smith, 2016). Social exclusion and isolation are increasingly recognised as threats to wellbeing and resilience in terms of health (Age UK, 2015). The rural geography of Cornwall and relatively poor availability and affordability of public transport compounds this isolation. Data on low wellbeing presents a worrying picture for Cornwall in terms of the economy, employment and wages, education and housing.

The CJNN project received funding from the European Social Fund delivered through the "Widening Participation through Skills" partnership. Funders required targeted involvement from within disadvantaged marginalised demographics from inside 'cold-spot' areas within Cornwall (European Social Fund, 2017). Cold-spot areas were identified as geographic regions where the uptake of places at level 4 of education were below national average. Marginalised and disadvantaged participants were identified as being from within the following demographic categories:

- Employed females

- Participants aged 54 and over

- Participants from ethnic minorities

- Participants with disabilities

- Single adult households with dependent children

In total the researchers worked with 67 people.

\section{Practice and Method: The CJNN Project}

The CJNN project did not adopt the tenet that impartiality is a prerequisite for journalistic reportage to be of value to society. Evidence of so-called unbiased 'professional' reportage is nothing more than an elaborate panacea deployed by commercial journalists to buttress against a public's clarion call for objectivity in the face of the central objective truth that all words selected and written by any individual at any time can only, by design, represent a subjective truth. This questioning of the central raison d'être of professional journalism through codesign is not explicitly intended to undermine the institutions and individuals who conduct a crucially important role in society through fulfilling the Sisyphean task of investigating and attempting to communicate external facts through a specific medium in the hope of inculcating a more balanced and informed society. The 
CJNN project simply attempts to throw the responsibility for attaining and evaluating such highly principled aims and aspirations firmly back into the realms of the social through DSI and co-design inspired collaborativeauthorship practices.

The CJNN hypothesis proposes that through foregrounding interesting new ways to generate co-authored news items via a bespoke DSI platform the research could relieve citizen journalists from some of the pressures and financial incentives of traditional journalism, e.g., having to be the first to publish a story, or to become the lone subject-specific expert/author within a defined journalistic field. The CJN app is an attempt to engage with some of the core issues described within this article through the implementation of iterative development processes to build a participatory platform through utilising representational state transfer (REST) application programming interface (API). Also known as RESTful web services, the REST API provides a file storage and retrieval system that is built upon a protocol that facilitates interoperability between different computer systems. The REST API system architecture allows for multiple points of access to the storage of data through different hierarchical levels of user privileges depending on the anticipated functionality of the app/website or database. Importantly REST APIs also facilitate synchronous access to the data stored on the system, which provides the ability for the system to grow while it is being accessed by multiple users.

Inherent Rest API infrastructural characteristics allow for collaboration between the citizen journalists but in order to fully realise the collaborative potential of the infrastructure the designers were required to develop an externally facing user interface that supported the intended practices. The CJN app integrated the Rest API characteristics into the user interface through labelling the forward-facing individual component media parts, such as images, text and metadata that come together to make up a journalism story as discreet 'fragments' (Figure 1). Within the app, fragments have the ability to be selected individually or configured into story 'clusters' by either the user or the audience. Individual fragments can be construed from various media types such as text, sound, images, films, and metadata, e.g., geographic location, tags, etc. (Figure 2), and each fragment represents one facet of the overall story, therefore the CJN app stores the fragments in a format which represents the story in a permanently unfinished state of becoming.

Users are able to assign story fragments to an identified, independent yet related story clusters that facilitate the aggregation of multiple fragments into thematic associations. Therefore, story fragments can be browsed as discrete objects by an interactive user as well as experienced from inside a collective format. Fragments and clusters may also be shared, assigned additional qualities and contributed towards by other users. The specific qualities of this collaborative ownership model of production are a deliberate incitement to disrupt the
OON

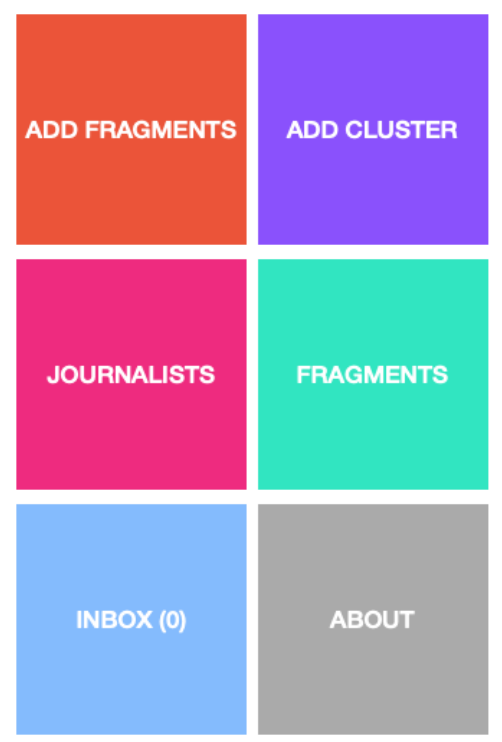

Figure 1. CJN home screen.

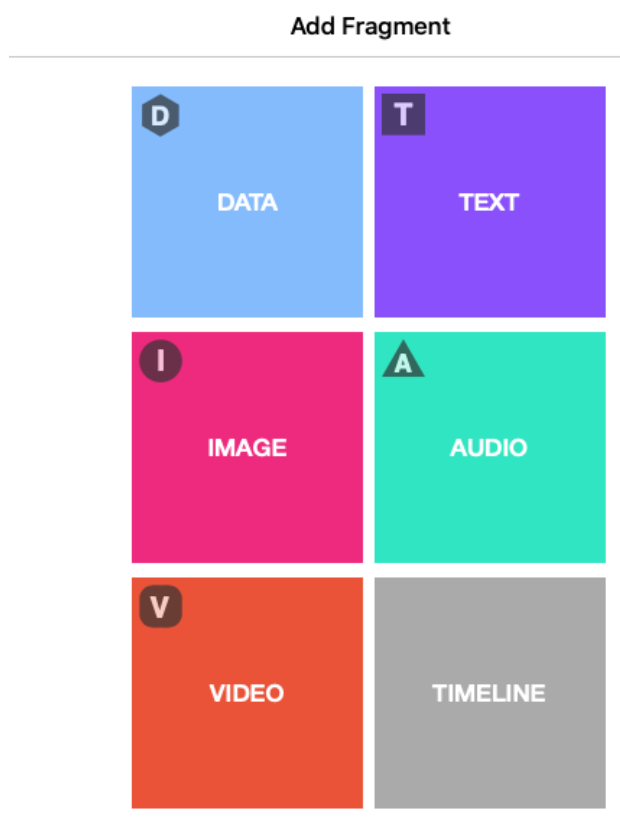

Figure 2. CJN fragment upload screen.

hegemony of the 24-hour news cycle within industrial news production. Through encouraging citizen journalists to contribute towards a shared story within an ongoing networked framework the CJN app provides an enticement to return to the story as the cluster expands over time as more citizen journalists contribute to the story. In this way, new industrial practices begin to assuage audience concerns around any perceived lack of journalistic impartiality through allowing a networked cluster of citizen journalists a participatory authorial role in the production of a story. Providing a networked oversight of story production facilitates greater 
levels of credence and believability through proffering multiple subjective viewpoints upon a single objective phenomenon. A similar methodology was successfully applied within the 2017 fact checking project called CrossCheck when 100 journalists from newsrooms around the globe monitored and collectively debunked false information around the French general election (Smyrnaios, Chauvet, \& Marty, 2017).

For members of the public consuming the forward facing CJN website (Figure 3), journalistic output can be accessed in a manner of their own choosing, for instance audiences can listen to a sound recording whilst looking through sets of images or data visualisation or reading some text on the subject. Rather than being associated with time-based news proliferation it was anticipated that using the CJN website would be similar to browsing an online archive. Researchers were interested in understanding to what extent innovative design could facilitate co-authorship and promote a fresh journalistic heterodoxy.

\section{Creating the News: Creating Places}

Journalism has a long history of identifying and commenting primarily on local or national issues and being supported through local/national business markets however the primary focus on local/national cultures has been reconfigured via the digital shift towards a more global/US-centric reframing of audience interests. The desire to engage with local and hyper-local interests remains a strong impulse within local communities how- ever the ability for larger organisations to control the news agenda with more sensational international stories is compelling to audiences and steers finances away from local news production causing a significant reduction in local news production (Boczkowski \& Mitchelstein, 2013). The globalisation of professional news agendas provided motivational considerations for members of the CJNN cohort as evidenced by this quote from one of the participants:

From the hyperlocal to the universal, the $\mathrm{CJ}$ could offer an alternative, thoughtful, authentic, contrary yet healing space for a creatively disruptive conversation between people where we, with care, listen to and tell our own and others' stories-with the purpose of cleaving the truth, as far as we can tell-from the spin, the hyperbole and the vested interest, as long as we understand and accept that we are just as vulnerable to such toxins as any other journalist.

Mobile computing and smartphone functionality offer citizen journalists multiple opportunities to substantiate their journalism claims through supplying the geo-locative metadata associated with their fragments. Geographic identification provides audiences and local media partners with the opportunity to browse stories from within their own geographical communities, allowing audiences to identify the scope of issues as they pertain to their own communities thus reconfiguring national stories within narrower local or regional frameworks. Perhaps more importantly, geolocating stories

\section{CJN HOME ABOUT}
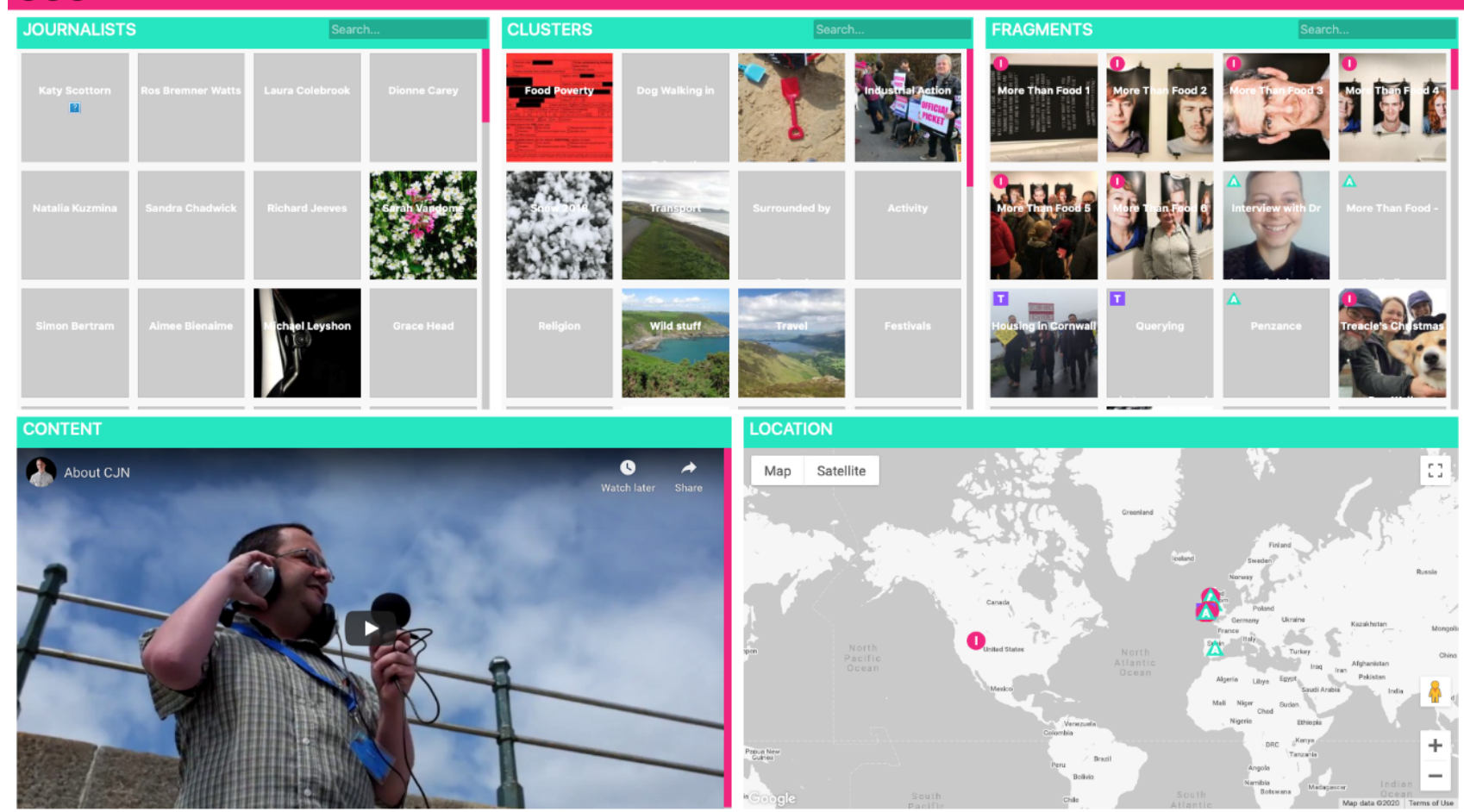

Figure 3. CJN website homepage. 
helped to facilitate opportunities for participants to identify place-based, person-centred approaches towards acknowledging and making visible specific issues of direct and significant importance within their own lived experiences from inside a knowable, hyper-local geographical framework. The research team operate within an ethical framework that dictates that an individual's specific geographic conditions and related opportunities and obstacles are an important defining factor in specifying their individual outlook, experiences and interests. Concrete practical examples of the place-based person-centred application of CJN related DSI are available within the geotagged artefacts uploaded to CJN website. In one such example a CJN user investigated the gentrification of small Cornish harbour town called Porthleven through first-hand experiential reportage (Osborne-Dowle, 2018) and in this way the CJNN project can be seen as an extended and ongoing application of a Participatory Action Research method by placing the participant at the centre of the decision making when selecting and identifying the issues of primary importance to themselves through reporting on their own lived situation.

Designing and developing large scale interactive communication platforms necessitates a detailed, subjectspecific understanding of the required call to action points and ongoing engagement motivations of potential users. Citizen journalism attracts a wide range of participants from professional journalists to complete beginners and inside each citizen journalist exists a complex range of personal motivations for instigating an involvement with a specific journalism project (Barnes, 2016). Whatever the motivation, every citizen journalist whether they know it or not is interested in entering into some form of reciprocal arrangement, which could be emotional reciprocity in the form of praise from their community and peers, or it could be practical forms of reciprocity such as improved employment opportunities, or it could be a form of philanthropic reciprocity achieved through witnessing personal stories come to life and facilitate positive change within communities (Borger \& van Hoof, 2016; Lewis, Holton, \& Coddington, 2013; Wall, 2017).

Understanding users' expectations around reciprocity and other forms of direct or indirect feedback are vital considerations when designing communication platforms (Harte et al., 2017). However, the designers of the CJN app were committed to attempting to avoid some of the familiar forms of incentive driven feedback loops that facilitate and encourage addictive and morally questionable behaviours within corporate platforms. Rather, the CJN platform was explicitly designed to encourage and enable the co-production of news stories, eschewing the inclusion of many well-known social media design practices that offer users a momentary sense of engagement and affirmation such as a 'likes' and other badge notifications. Instead, there was expectation that satisfaction and a sense of reciprocal engagement would be available through collaborative practice, networking and the wider dissemination of story fragments through an explicit partnership connection with professional and community broadcasting organisations.

However, the ability to share story fragments and clusters with a wider community outside of the app infrastructure was deemed to be of critical importance to the reciprocal principles of the project. Upon reflection, the noble ideals and creative restrictions upon which the design and development stages of building and testing the CJN app are operating were not supported by sufficient primary research with the intended users. This may have resulted in a lack of ongoing engagement with the platform once the CJNN project had completed. Attempting to design platforms against established reciprocal paradigmatic frameworks that exist within popular multinational social media platforms was overly optimistic and representative of a somewhat hubristic idealism on the part of the development team.

The research applied a mixture of content analysis, textual analysis and narrative analysis methods to enable a close reading of the texts submitted within the CJN app. The content analysis was cross-referenced against additional data fields including geolocation information as well as any perceived cluster associations that are made available through the author 'tagging' content with categorical field information. Interrogation of the content submitted to the CJN app alongside the geographical context within which that content was submitted enabled researchers to specifically assess the textual qualities of the fragments and identify and record any references to, or lack of reference to, the following relevant textual, narrative and geographic themes:

- Hyper-local/local/national or international references of place.

- A direct reference by the citizen journalist towards a personal interest or involvement with the chosen subject matter.

- An address by the citizen journalist towards an identified community that exists within a geographic framework that can be considered as local to the reporter.

- An address towards an identified community that exists within a geographic framework that can be considered as international.

To minimise the range of potential interpretations on offer the research applied categorical stipulations for each of the textual/narrative themes. Hyper-local/local/ national or international references of place are measured straightforwardly in the following ways:

Category 1(A). Any text which contains imagery, sounds effects, verbal or written mentions of a hyperlocal' environment $=$ any text that is identifiable as falling within a 5-mile radius of the journalists lived environment. An example of this is where the journalist states: "We have looked into the history of the 
Penzance promenade and why it is not used to its full potential since completion in 1893."

Category $1(\mathrm{~B})$. Any text which contains imagery, sounds effects, verbal or written mentions of the 'local' environments = any text that is identifiable as originating from within Cornwall but outside of the 5-mile radius 'hyper-local' definition geographic boundaries. An example of this is where the journalist states: "I decided to talk about ocean pollution and the visible effects that it has to Cornish beaches. Through my research I had noted that many beaches outside of my local area had planned many beach clean-up events where the public was encouraged to go and clean the beach in an organised group."

Category $1(\mathrm{C})$. Any text which contained imagery, sounds effects, verbal or written mentions of a 'national' environments = any text that is identifiable as originating outside of Cornwall but still geographically identifiable as originating from within the UK. An example of this is a piece by citizen journalist Tracey Johnson on the CJN app where Tracey interviews someone in Birmingham about music culture (Johnson, 2018).

Category 1(D). Any text which contained imagery, sounds effects, verbal or written mentions of an 'international' environment, meaning any text that is identifiable as originating outside of 'national' UK boundaries is considered to fall within this category. An example of this is a piece by citizen journalist Rob Shapland-Hill (2018) on the CJN app where Rob spends a day exploring the city of Cartagena in Spain.

In order to qualify as a direct reference towards a personal interest or involvement with the chosen subject matter by the reporter, the researcher would be expected to have been able to identify, either through the texts or associated reporting on the subject matter, a directly citable source where the journalist makes a claim towards a direct and personal relationship with the subject matter. A powerful example of this is available in the piece on domestic violence called "\#Survivor" (Richardson, 2018) on the CJN website.

Subjects of interest to the wider community local to the reporter is a more speculative category. This is an attempt to differentiate and identify a journalistic address towards a local audience through selecting a subject matter that can be rationalised as being of interest to a local audience but not of interest to a national or international audience. It could be argued that this category is simply a reframing of the 1st category however it was felt that the slight reframing of the research question could allow for a more nuanced interpretation of the data.

The results of the content analysis (Table 1) point towards some interesting trends and dynamics within the study group of 67 people.

There was a strong propensity to create journalism that contains (either) imagery, sound effects, verbal and/or written mentions of a 'hyper-local' environment with over $66 \%$ of the work submitted falling within category $1(A)$, including fragments such as John Pestle's (2018) short report about a housing march from Newlyn to Penzance. Perhaps unsurprisingly the percentage of the study group utilising a direct mode of address towards an identified local community (62\%) almost directly mirrors the percentages for mentions of a hyper-local environment, fragments from this category included fragments such as David Hill (2018) reading a community noticeboard for West Penwith. However, $46 \%$ of the work submitted also contained either imagery, sounds effects, verbal and/or written mentions of a 'local' environment with fragments in this cate-

Table 1. Results of the content analysis of CJN fragments.

Categories and Definitions

Number of instances stories of this categorisation were

Category $1(A)=$ Any text which contains imagery, sounds effects, verbal or written submitted to the CJN app mentions of a 'hyper-local' environment

Category $1(B)=$ Any text which contains imagery, sounds effects, verbal or written mentions of a 'local' environment

Category $1(\mathrm{C})$. Any text which contained imagery, sounds effects, verbal or written 10 mentions of a 'national' environment

Category $1(D)$. Any text which contained imagery, sounds effects, verbal or written mentions of an 'international' environment

A direct reference towards a personal interest or involvement with the chosen subject matter by the reporter

Direct address towards an identified local community

Direct address towards an identified international audience 
gory including John Pestles image from a Save the NHS Rally in Truro (Pestle, 2018). However, only $29 \%$ of the work submitted referenced national environments and an example of a fragment from Category $1(\mathrm{C})$ include work such as Neil Berry's (2018) news report from his "Easter Podcast." 34\% of the work referenced international environments however this was always associated with personal travel and/or historical experiences of living inside those international environments, such as Rob Shapland-Hill's visit to Cartagena in Spain. Almost $50 \%$ of the members of the study group made a piece of journalism that in some way makes a direct reference towards a personal interest or involvement with the chosen subject matter by the reporter such as Sarah Vandome's piece titled "Tregassic Winter Walk" (Vandome, 2018). As with mainstream news outlets the work submitted through the CJN app falls into the categories of either 'hard' or 'soft' news. The hard news submitted via the CJN app provides a number of examples of what we would categorise as 'protest journalism' as evidenced by the work submitted by Osborne-Dowle (2018), Pestle (2018) and Richardson (2018) that challenge the established and more normative mainstream discourses used in place-making.

The content analysis draws attention to the ability of using the predominantly hyperlocal focus of citizen journalists as a method for challenging the predominantly national and international focus of mainstream media outlets. The CJN platform uses issues-based reporting as a DSI to identify a geography of what matters in peoples first-hand, person-centred experiences. Geographic distances often dislocate the majority of an audience from the core focus of an international and nationally focused news agenda. National and international issues and national/regional modes of news address are significantly more challenging for citizen journalists to conceptualise and meaningfully reproduce. Therefore, there is a disjuncture between broadcast news that simply coerces audiences into large scale international and nationalistic discourses, and localised forms of self-produced news that serve to empower hyperlocal communities. DSI improves opportunities for representation and de-centers the politics of news and news mediation.

\section{Discussion}

Some of the broader intentions of the CJNN project cannot be claimed as having achieved success within this iteration phase, for example there was very little evidence of the app facilitating collaborative authorship despite the explicit design intentions to foster precisely this type of behaviour. Also, no research has been undertaken at this stage to evaluate whether audiences of any of the journalistic output of the project felt concern or reassurance around the lack of objective impartiality of the journalism that they were consuming via the $\mathrm{CJN}$ website due to the open-source, non-professional, collaborative authorial potential of the CJNN project. There was some evidence of participants revisiting story themes and clusters over a longer period to contribute new story fragments towards the development and deepening of existing story clusters and therefore broadening the discourse around a newsworthy subject in a way that could be considered as contrary to the established 24-hour news cycle, an example of this can be found in the way that CJNN journalist Christiana Richardson (2018) contributed multiple items to the cluster on domestic violence over a four month long period, however it would be tenuous to claim these rare and isolated examples as evidence of an emerging new journalistic heterodoxy.

We set out in this article to explore how DSIs offer the possibility for (urban) places to become more participatory and equitable (Phills, Deiglmeier, \& Miller, 2008) through providing a framework for citizen journalism to flourish in contingent places such as pubs, landscapes, shops and social media (Wall, 2017). The CJNN digital intervention offers people living in economically deprived places the opportunity to produce their own news content and diverge from more traditional national media sources. Such localised forms of meaning and place-making are produced by gathering and sharing stories, images, and sounds. Platforms provide a site for the reproduction of place, in the case of the CJN app it was a focal point to address local issues and concerns. This presents several challenges for digital social innovators. Platforms host a range of individual and institutional aims, objectives and contexts that vary in considerable ways. Managing different expectations of actors may become problematic. DSIs like the CJN app can support 'soft' rather than radical change, in which small scale action is grounded in local places. Thus, programmes like CJNN have a disruptive power that enables individuals to bring their interests, concerns and knowledges together in inventive, reciprocal, and collaborative ways.

This research draws attention to the latent need for hyperlocal-news reportage, especially for marginalised groups whose voices are often absent in the mass media. Indeed, hyperlocal reporting is one way of engaging individuals to question the authority and 'trustworthiness' of news (Harrison, 2017) through creative, authentic and issues-based reporting. It also provides, via the CJN app, a new platform for the geography of news that matters in people's lives. The CJNN digital invention makes this possible by offering a person-centred approach to news mediation. However, this does not result in the overwriting of other news sources, rather it becomes part of a more complex local ecology of news production, social media and discourse that reconstitutes notions of community and belonging. These new emergent ecologies could provide a fruitful area for future research on DSI.

While there has been a push for evidence-based approaches to the integration of localised forms of knowledge in formal academic assessments, positivistic science still devalues local knowledges and does not recognize its centrality in the ongoing process of adaptation to major issues. Too often, news stories re-enact the 
extractive nature of national media colonialism through the dominance of what is deemed worldview worthy by writing on behalf of local communities. We argue that explicit attention needs to be paid to differential story-telling strategies, through a range of mediums, e.g., sound, text and image, to democratise news production and mediation. As expected, although the CJNN project pilot supplied a mixed range of responses and inconclusive research findings, however it also supplied ample examples of potential improvements to the project for future iterations. Over the two-year-long duration of the project the research points towards one truly collaborative journalistic effort involving multiple citizen journalists in multiple hyperlocal environments. The story cluster that facilitated the mass collaboration was about an unusual weather event that affected the entire geographic area of Cornwall and impacted multiple individuals simultaneously. Therefore, it can be hypothesised that multiple levels of simultaneous impact upon participants facilitates and incentivises collaborative engagement. This hypothesis is evidenced within other common themes for collaboration within the app that also included popular activities such as travel, transport, the environment, history and heritage. Many of the remaining cluster themes such as domestic abuse, food poverty, industrial action and political campaigning can be considered a more highly niche or specialist interest for citizen journalists. It is anticipated that a significantly larger number of participants and a geographically wider dissemination and engagement programme could increase the amount of active collaboration and co-authorship as shared interests become more apparent within a larger study group.

\section{Conclusion}

The CJNN project is an example of DSI from the ground up in which individuals are included in the co-design and development of a local journalism platform. Such platforms provide the potential to support community efforts to produce a sense of place through sharing stories and images that reflect the lived realities of peoples' lives. However, there is a caveat to this interpretation. Unfolding in the EU is a real-time illustration of the fallacy of technological determinism, exemplified by the CAPS project amongst many. Technologies do not, in and of themselves, influence improvements in urban policy, health and wellbeing, prevent disease, protect the vulnerable or connect people together in meaningful pro-social ways. This is especially true when they bypass existing socio-technical infrastructure. The greatest fallacy is to assume that technology is, in and of itself, egalitarian. Indeed, there is a strong 'technologically enhanced' rhetoric running through social innovation policy (Walker, Esmene, Colebrooke, Leyshon, \& Leyshon, $2020)$ that posits if only structural connectivity problems can be overcome then social ills can be solved. However, apps can just as easily create social anxiety, uncertainty, and atomise individuals. Hence, we must be careful not to rely on DSIs to simply replace the material social realities of individuals' lives through creating ever more 'virtual platforms' for dialogical purposes, because by doing so we will detach individuals from the subjective judgements and contributions they may be able to make to improve their urban environments. While we do not assume that DSIs will ameliorate all social problems, they can be an essential component in empowering and mobilising engaged individuals to create cities of digital innovation, in which practical actions maximise local resources to build progressive places.

DSI is often conceptualised as a social good with the potential to produce new and, by inference, better, 'state/organisation/individual' social partnerships that are delivered at a local level (Angelidou \& Psaltoglou, 2017). Co-produced bespoke services are being designed and implemented through partnerships between service users and residents and a range of service providers. As illustrated in our CJNN example, DSI is positioned as an opportunity for individuals to influence fast policy responses via reporting change in their local neighbourhoods. DSI platforms like the CJNN are conceived as a "space of agency" from which social action can be mobilised, organised and delivered (Joseph \& Skinner, 2012, p. 387). Success for such projects requires that individuals work outside their normal practices and beyond established organisational silos. As we discussed above, this is necessarily disruptive to business-as-usual and it generates a certain amount of productive anxiety that pushes individuals and communities to rethink their practices. The CJNN allowed individuals the freedom to innovate, to generate a space to foster social relations and produce new forms of social responsibility for local issues and environments.

Finally, this article represents a tentative step to move beyond the dichotomous perspectives of an uncritical technology-driven optimism of smart innovation as a universal panacea (Aitamurto, 2012) and the radical criticism and dissatisfaction with the 'wisdom' of the crowd (Lanier, 2006). By doing so, we contribute to debates on how DSIs help reconfigure notions of place by drawing individuals, hitherto distant from active placemaking, into the production processes of how places are made and remade through story telling. Our work also highlights the potential of how DSIs could challenge the way that knowledges are embedded in social institutions (Naess, 2013), forms of place-making (Tracey \& Stott, 2017), reciprocal relationships and practices with a more 'organic' bottom-up approach to identifying the needs of local people (Harte et al., 2017). DSIs, like the CJNN, identify more imaginative ways of using existing resources and solving problems that have implications for society. In this regard it is no coincidence that DSIs have taken-off just as governments and cities have less scope for spending and are seeking to cut back on public finances. However, while some academics dismiss social innovation on this basis, arguing that it is a cover for a 
state in retreat, we are advocating a less pre-committed approach to understanding these trends. It is important to explore the role of DSIs and assess their impact on a case-by-case basis. In so doing, there is a role for urban scholars to map out the emergence of this new form of social practice and the impact it is having without prejudging its outcome.

\section{Acknowledgments}

We would like to thank the two anonymous referees and the journal editors for their helpful and insightful comments. We would also like to thank Professor Catherine Leyshon for commenting on an earlier draft of this article. The research was funded by the European Social Fund's (ESF) project "Widening Participation Through Skills" (Project Reference: 05S15P00221).

\section{Conflict of Interests}

The authors declare no conflict of interests.

\section{References}

Age UK. (2015). Testing promising approaches to reducing loneliness. London: Age UK and the Campaign to End Loneliness. Retrieved from https://www.ageuk. org.uk/documents/en-gb/services/loneliness/ testing_promising_approaches_to_reducing_ loneliness_report_2016.pdf?dtrk=true

Aitamurto, T. (2012). Crowdsourcing for democracy: $A$ new era in policy-making (Parliament of Finland 1/2012). Helsinki: Committee for the Future, Parliament of Finland. Retrieved from https://ssrn.com/ abstract $=2716771$

Anderson, C. W., Bell, E., \& Shirky, C. (2012). Postindustrial journalism: Adapting to the present. Tow center for digital journalism. New York, NY: Columbia Journalism School.

Angelidou, M., \& Psaltoglou, A. (2017). An empirical investigation of social innovation initiatives for sustainable urban development. Sustainable Cities and Society, 33(August), 113-125.

Barnes, R. (2016). The imagined community of readers of hyperlocal news: A case study of Baristanet. Journal of Alternative and Community Media, 1(1), 84-96.

Berry, N. (2018). Easter podcast thing. CJN. Retrieved from https://cjn-front-end-demo.herokuapp.com/ fragment/5abb9b58758d170778127119

Boczkowski, P., \& Mitchelstein, E. (2013). The news gap: When the information preferences of the media and public diverge. Cambridge, MA: MIT Press.

Borger, M., \& van Hoof, A. (2016). Expecting reciprocity: Towards a model for the participants perspective on participatory journalism. New Media and Society, 18(5), 708-725.

Bria, F. (2015). Growing a digital social innovation ecosystem for Europe (DSI Final Report). Brussels: Eu- ropean Commission. Retrieved from https://media. nesta.org.uk/documents/dsireport.pdf

Cabinet Office. (2018). Civil society strategy: Building a future that works for everyone. London: HM Government. Retrieved from https://www.gov.uk/ government/publications/civil-society-strategybuilding-a-future-that-works-for-everyone

Cangiano, S., Romano, Z., \& Loglio, M. (2017). The growth of digital social innovation in Europe. An open design approach to support innovation for the societal good. The Design Journal, 20(1), 3546-3559.

Cataldo, M. (2016). Gaining and losing EU Objective 1 funds: Regional development in Britain and the prospect of Brexit (LEQS Paper No. 120/2016 November). London: LEQS. Retrieved from http://www. Ise.ac.uk/europeanInstitute/LEQS\%20Discussion\%20 Paper\%20Series/LEQSPaper120.pdf

Cornwall and Isles of Scilly Leadership Board. (2019). Digital inclusion strategy for Cornwall and the Isles of Scilly 2019-2023. Truro: Cornwall Council. Retrieved from https://www.cornwall.gov.uk/media/ 36991917/digital-inclusion-45050-web.pdf

Cornwall Council. (2015). Indices of multiple deprivation 2015: Headline data for Cornwall. Truro: Cornwall Council. Retrieved from https://www.cornwall.gov. uk/media/40596801/imd-2019-cornwall.pdf

Department of Culture, Media and Sport. (2017). UK digital strategy 2017. London: HM Government. Retrieved from https://www.gov.uk/government/ publications/uk-digital-strategy/uk-digital-strategy

Dodd, J. (2015). About the new reality. The New Reality Project. Retrieved from https://thenewreality.info/ about-new-reality

Downing, J. (2001). Radical media: Rebellious communication and social movements. Thousand Oaks, CA: Sage.

Dwyer, P., \& Wright, S. (2014). Universal credit, ubiquitous conditionality and its implications for social citizenship. Journal of Poverty and Society Justice, 22, 27-35.

Edwards-Schachter, M., \& Wallace, M. (2017). 'Shaken, but not stirred': Sixty years of defining social innovation. Technology Forecasting and Social Change, 119(June), 64-79.

Enders, C. (2011). Competitive pressures on the press: Presentation to the Leveson inquiry. London: Enders Analysis.

European Social Fund. (2017). Widening participation through skills: Project objectives. Plymouth: European Union. Retrieved from https://www.plymouth. ac.uk/business-partners/business-services/ enterprise-solutions/case-studies/esf-wideningparticipation-skills-partnership-project-objectives

Evans, P. C., \& Gawer, A. (2016). The rise of the platform enterprise: A global survey (The Emerging Platform Economy Series 1 CGE Report). New York, NY: The Center for Global Enterprise. Retrieved from https://www.thecge.net/app/uploads/2016/01/PDF- 
WEB-Platform-Survey_01_12.pdf

Forde, S. (2011). Challenging the news: The journalism of alternative and community media. Basingstoke: Palgrave Macmillan.

Harrison, A. (2017, August 6). Can you trust the mainstream media? The Guardian. Retrieved from https://www.theguardian.com/media/2017/aug/ 06/can-you-trust-mainstream-media

Harte, D., Williams, A., \& Turner, J. (2017). Reciprocity and the hyperlocal journalist. Journalism Practice, 11(2/3), 160-176.

Hess, K., \& Waller, L. (2016). Hip to be hyper. Digital Journalism, 4(2), 193-210.

Hill, D. (2018). What's on diary. CJN. Retrieved from https://cjn-front-end-demo.herokuapp.com/ fragment/5a85d5293dcc430010ed5b91

Johnson, T. (2018). Cultures. CJN. Retrieved from https://cjn-front-end-demo.herokuapp.com/ fragment/5ab18415758d170778127114

Joseph, A., \& Skinner, M. (2012). Voluntarism as a mediator of the experience of growing old in evolving rural spaces and changing rural places. Journal of Rural Studies, 28(4), 380-388.

Lanier, J. (2006). Digital Maoism: The hazards of the new online collectivism. The Edge. Retrieved from https://www.edge.org/conversation/jaron_lanierbeware-the-online-collective

Lewis, S. C., Holton, A. E., \& Coddington, M. (2013). Reciprocal journalism: A concept of mutual exchange between journalists and audiences. Journalism Practice, 8(2), 229-241.

Lloyd, G., Jochum, V., \& Hornung, L. (2017). Digital technology and the voluntary sector: Disruption, transformation and maturity. London: National Council for Voluntary Organisations.

Mason, C., Barraket, J., Friel, S., O’Rouke, K., \& Stenta, C. (2015). Social innovation for the promotion of health equity. Health Promotion International, 30(2), 116-125.

McCollough, K., Crowell, J., \& Napoli, P. (2017). Portrait of the online local news audience. Digital Journalism, 5(1), 100-118.

Moulaert, F., Mehmood, A., MacCallum, D., \& Leubolt, B. (2017). Social innovation as a trigger for transformations: The role of research in the European Commission Directorate-General for research and innovation directorate $B$. Brussels: Open Innovation and Open Science Unit B.6, European Commission.

Moulaert, F., Swyngedouw, E., Martinelli, F., \& Gonzalez, S. (Eds.). (2010). Can neighbourhoods save the city? Community development and social innovation. London: Routledge.

Mulgan, G. (2006). The process of social innovation. Innovations, 2006(Spring), 145-162.

Muller, E., \& Peres, R. (2019). The effect of social networks structure on innovation performance: A review and directions for research. International Journal of Research in Marketing, 36(1), 3-19.
Naess, L. O. (2013). The role of local knowledge in adaptation to climate change. Wires Climate Change, 4(2), 99-106.

Osborne-Dowle, S. (2018). Space2Dream. CJN. Retrieved from https://cjn-front-end-demo.herokuapp.com/ fragment/5d727e1d602b1141fb3f2a32

Papacharissi, Z. (2014). Affective publics: Sentiment, technology and politics. Oxford: Oxford University Press.

Pestle, J. (2018). Housing in Cornwall. CJN. Retrieved from https://cjn-front-end-demo.herokuapp.com/ fragment/5a805906609829001ad4aa76

Phills, J. A., Jr., Deiglmeier, K., \& Miller, D. T. (2008). Rediscovering social innovation. Stanford Social Innovation Review, 6(4), 34-43.

Richardson, C. (2018). \#Survivor. CJN. Retrieved from https://cjn-front-end-demo.herokuapp.com/ fragment/5ae1d318c8a1933b6171ed75

Schon, S., Ebner, M., \& Hornung-Prahauser, V. (2017). Digital social innovation within education: Five insights on the role of digital tools in the field of Open Educational Resources (OER) projects. Progress in Education, 49, 167-188.

Shapland-Hill, R. (2018). A day in Cartegena. CJN. Retrieved from https://cjn-front-end-demo.herokuapp. com/fragment/5aeb0ef4c8a1933b6171ed77

Smyrnaios, N., Chauvet, S., \& Marty, E. (2017). The impact of crosscheck on journalists \& the audience. Cambridge, MA: Harvard Kennedy School.

Tracey, P., \& Stott, N. (2017). Social innovation: A window on alternative ways of organizing and innovating, Innovation. Organization and Management, 19(1), 51-60.

Travers-Smith, F. (2016). Abandoned communities. London: Move your money. Retrieved from https:// financialhealthexchange.org.uk/wp-content/ uploads/2016/07/Abandoned-Communities.pdf

Turnbull, B. (2016). Impact of universal credit: Report 1. Sunderland: Northern Housing Consortium. Retrieved from https://www.northern-consortium. org.uk/influencing/impact-of-universal-credit

Vandome, S. (2018). Tregassic winter walk. CJN. Retrieved from https://cjn-front-end-demo.herokuapp. com/fragment/5a9830ea758d1707781270e3

Walker, T., Esmene, S., Colebrooke, L., Leyshon, C., \& Leyshon, M. (2020). Digital possibilities and social mission in the voluntary sector: The case of a community transport organisation in the UK. Voluntary Sector Review, 11(1), 59-77.

Wall, M. (2017). Mapping citizen and participatory journalism. Journalism Practice, 11(2/3), 134-141.

Wallace, J. (2018). Modelling contemporary gatekeeping: The rise of individuals, algorithms and platforms in digital news dissemination. Digital Journalism, 6(3), 274-293.

Williams, A., Harte, D., \& Turner, J. (2015). The value of UK hyperlocal community news. Digital Journalism, 3(5), 680-703. 


\section{About the Authors}

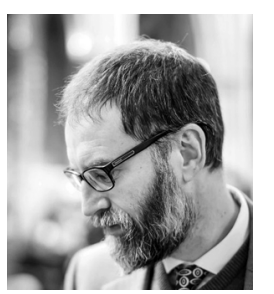

Michael Leyshon is a Social Geographer and Co-Director of the Social Innovation Group at the University of Exeter. His research explores how third sector agencies and small businesses innovate to produce social change. In particular his work seeks to ground place-based person-centred approaches in a variety of locations, practices and performances, by focusing on issues relating to care and volunteerism, and business adaptation to climate change.

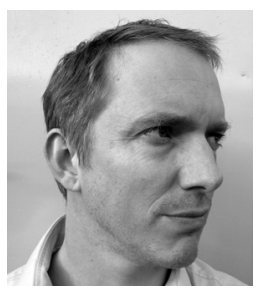

Matthew Rogers is a member of the Social Innovation Group (SIG) at the University of Exeter, where he works as a Post-Doctoral Researcher in the areas of Citizen Journalism and Platforms. He has also written an online course in Podcasting. Matthew is also a Senior Lecturer at Falmouth University where he teaches on the BA(Hons) Television degree. 